\title{
Trusting neighbours or strangers in a racially divided society: Insights from survey data in South Africa
}

\author{
Dorrit Posel and Tim Hinks \\ University of KwaZulu-Natal and University of the West England
}

July 2011

\begin{abstract}
In this paper, we investigate reported measures of trust in South Africa, collected in the 2008 National Income Dynamics Study. In particular we compare responses to two questions asked of all adult respondents about the likelihood that a lost wallet or purse containing 200 Rand will be returned either by "someone who lives close by" or by a "complete stranger". Although reported levels of trust are very low, we find that South Africans are significantly more likely to report trusting neighbours than strangers. We use ordered probit regressions to estimate the determinants of these two measures of trust. Consistent with studies from the U.S. and from South Africa, we find considerable racial variation in reported trust. In comparison to Whites, other population groups in South Africa are significantly less likely to report trusting people who live close by. However, these racial differences are dramatically reduced once differences in personal and neighbourhood income are controlled for. In contrast, racial differences in trust of strangers are smaller, and differences are even reversed among Black South Africans, who appear more trusting than other population groups of strangers. Because the majority of the population is Black, respondents may assume that a complete stranger is Black, and this finding would therefore be consistent with in-group favouritism, where individuals are relatively more likely to trust people who belong to their own population group.
\end{abstract}




\section{Introduction}

Over the past twenty years, a large literature has developed on the economic effects and the determinants of trust. Studies have found that the level of trust in a society is associated with a range of positive outcomes, including increased economic growth (Knack and Keefer 1997, Knack and Zak 2001), greater judicial efficiency and reduced government corruption (LaPorta et al 1997). Understanding the determinants of trust helps explain differences in levels of trust across societies and may be relevant in identifying ways in which trust can be promoted.

In this paper, we explore the determinants of trust in South Africa, a society characterised by historically entrenched racial divisions in access to resources and persistent residential segregation along racial lines. Although Blacks have significantly lower economic status than Whites, they also constitute the majority population in South Africa. Previous research on trusting behaviour in South Africa has used experimental games and has identified large racial differences in trust, with Black participants being less trusting than Whites, and surprisingly, less trusting of other Blacks than of Whites (Burns 2006). We revisit racial differences in trust making use of a nationally representative household survey which, for the first time in South Africa, includes questions that probe attitudes to trust.

Although an increasing number of studies analyse trust in strategic settings, attitudinal questions asked in surveys remain an important source of data for investigating the determinants of trust. These data reflect the heterogeneity of the population, and data on trust are collected alongside a wide array of information on individual, household and community characteristics. Most studies which use attitudinal data to investigate the determinants of trust analyse answers to the World Values Survey and the U.S. General Social Survey question, "Generally speaking, would you say that most people can be trusted or that you can't be too careful?". In contrast, we analyse two survey questions which distinguish between trust in people who live close by, and trust in people who are strangers, and which specify a particular scope of trust, viz. the likelihood that a lost wallet will returned.

In the next section, we review evidence on the relationship between trust and race, and in section 3 we discuss the South African context as well as the specific survey questions which are analysed in the study. In section 4, we describe the data and the econometric methods used to estimate the determinants of trust and in section 5, we present and discuss the results of the estimations. The final section concludes by summarising the key findings.

\section{Trust and race: a brief review}

A common finding from studies of trust in the U.S. is that there are significant race differences in people's willingness to trust. In particular, $t$ Part of the explanation for these race differences is that there are a range of individual and community 
characteristics which vary by race and which also influence trusting behaviour. For example, people's willingness to trust is found to increase significantly as their education and income increase, and average levels of education and income are far lower among Blacks than among Whites living in the U.S. Blacks are also more likely to live in poorly resourced and racially fragmented neighbourhoods, factors which may further undermine levels of trust.

Controlling for individual and neighbourhood characteristics therefore typically is found to reduce estimated race differences in trust. However, significant differences still remain. A key explanation for this persistence is that individuals who are members of a discriminated or disadvantaged group are less likely to trust individuals from another group because of the discriminatory or disadvantageous treatment they have received in the past (Demaris and Yang 1994; Brehm and Rahn 1997, Alesina and La Ferrara 2002). Past experiences may influence expectations of trusting behaviour not just of the individuals directly affected but also of their children.

In estimating the correlates of trust, most studies make use of attitudinal data on trust collected in surveys. The standard survey question asked in the World Values Survey (WVS) and in the U.S. General Social Survey is as follows: "Generally speaking, would you say that most people can be trusted or that you can't be too careful in dealing with people?"1 This question is meant to provide a measure of generalized trust, capturing "a default expectation of other people's goodwill" (Miller and Mitamura 2003:62), or the ability to extend trust "beyond specific personal settings in which the partner to be cooperated with is already known" (Marschall and Stolle, 2004:128).

However, a number of problems with the survey measure have been identified in recent years. The first set of problems concerns what the standard survey question actually measures. Research by Glaeser et al (2000) contrasts responses to the standard survey question and trusting behaviour revealed through experimental games among a group of Harvard university students. The study finds that the standard survey response corresponds to the trustworthy behaviour (the ability to be trusted) of the respondent rather than to the respondent's trust in others. This finding, however, has not been consistently corroborated in subsequent experimental studies. In a modified trust game, where senders are asked to report on their beliefs about the receiver's behaviour, for example, Sapienza et al (2007) find that the standard survey question is correlated with the expected trustworthiness of the receiver, and not with that of the sender (see also Fehr et al 2003). A possible explanation for the different results concerns the composition of the samples analyzed. In Glaeser et al's (2000) study, the sample is a largely homogenous group of students, where knowledge about other players is high and where "players tend to form their expectations by introspecting (from) their own behaviour" (Sapienza et al 2007:3). But this may not be true of more heterogeneous populations and where there is low mutual knowledge among players.

\footnotetext{
${ }^{1}$ Sapienza et al. (2007) estimate that at the time of writing their paper, at least 500 studies had measured trust using the data collected from these two surveys.
} 
Concerns have also been raised about whether the standard survey question elicits information about trust versus distrust. Miller and Mitamura (2003:63), for example, suggest that "the two halves of this question are conceptually distinct". Whereas the first half requires respondents to reflect on the general trustworthiness of other people, the second half requires an assessment of the respondent's willingness to take risks (ibid: 64).

A second set of problems, which has clear implications for interpreting race differences in trust, concerns the reference category or the radius of trust implied by the standard survey question. The survey asks people to identify whether "most people" can be trusted, but it is not clear how respondents would imagine "most people" in their response. If this is interpreted as representing the majority population, then the measure of trust collected through the standard survey question will not capture generalized trust, but trust of the majority group (Simpson et al 2007). For example, where the majority population is White, as is the case in the U.S., then "most people" may be associated with "White people" by both White, and Black, respondents. Whites would be reporting on their general levels of trust of other Whites, and Blacks would be reporting on their general trust of Whites. In this case, measured race differences in trust will reflect race differences in characteristic-based (Zucker 1986) or particularized trust.

In general, studies on particularized trust find that individuals are more likely to trust others who they perceive as similar to themselves. In a number of studies which run the trust or investment game, for example, trust is higher when people from the same group interact (cf. Glaeser et al 2000, Simpson et al 2007, Vollan 2011). Findings from these studies suggest an in-group bias, the converse of which is that people "are more likely to regard out-group members ... with suspicion, and they stereotype them more readily and negatively" (Tschannen-Moran and Hoy 2000: 561). Group identity can be formed along a number of different lines, including race, gender, ethnicity, kinship and nationality. Among these different markers, race has been found to be particularly important (Uslaner 2002; Smith 2010). ${ }^{2}$ However, studies do not consistently find lower levels of in-group or out-group trust among Blacks, thus challenging findings on race differences in trust derived from the standard survey question (cf. Simpson et al 2007).

\section{South Africa: Context and data}

South Africa offers a particularly interesting context to explore race differences in trust. With a long history of apartheid and systematic discrimination, Whites have long occupied an economically advantaged position in society. Notwithstanding the transition to democracy in 1994, the legacy of apartheid persists in the access to and quality of educational attainment and employment. Furthermore, although residential segregation along race lines is no longer enforced, this segregation largely continues, at least in part because of sustained differences in socio-economic status.

\footnotetext{
${ }^{2}$ In the relatively new field of neuroeconomics where cognition and affect can be seen by brain imaging and measuring magnetic, electrical or water activity in the brain, it has been found that people of different racial groups have an emotional dislike of other racial groups (Phelps et al, 2000; Hart et al, 2000).
} 
Unlike in the U.S., Black Africans constitute the majority group in South Africa, accounting for approximately 80 per cent of the total population. Whites, Indians and Coloureds comprise minority groups; but Whites are a distinctive minority, both because of their relatively higher socio-economic status and because they are less geographically concentrated than the two other racial minorities. The majority of Coloureds are located largely in the province of the Western Cape (where Coloureds also comprise a greater share of the population than Blacks), while most Indians live in the province of KwaZulu-Natal.

In addition to very high levels of poverty, inequality and unemployment (cf. Casale et al 2004, Hoogeveen and Özler 2006, Leibbrandt et al 2006), South African society is characterized by crime rates that are amongst the highest in the world (Demombynes and Özler 2005). Evidence from Demombynes and Özler (2005) suggests that inequality, unemployment and poverty in South Africa are all correlated to crime at the police precinct or criminal catchment area level. Those precincts with the highest household expenditure are more likely to suffer from high rates of burglary indicating that the expected return from property crime is one of the causes of higher burglary rates. In addition, precincts with greater racial heterogeneity are more likely to have higher levels of all criminal activity.

Given these findings and the apartheid history, we might expect very low levels of generalized trust in South Africa, but strong evidence of particularized trust within race groups. However, there has been little research which has investigated trust in the country, partly because questions on trust were not included in the nationally representative household surveys, administered regularly since 1993. A key study is that conducted by Burns (2006), who used an experimental design to explore race differences in trust.

Burns ran the trust game on a sample of high school students in the greater Cape Town area, but she also administered survey-type questions on trust to participants. Data from the self-reported survey questions show that Black students are less likely than White and Coloured students to report that "most people can generally be trusted". Lower levels of inter-personal and community trust were also reported by Black students, who surprisingly, were more likely to report that they would trust other race groups than their own race group. Findings from the trust game largely corroborate these self-reported measures. In the trust game, Blacks students made and received significantly lower offers than White or Coloured students (Burns, 2006:810). Furthermore, Black students made lower offers to Black partners, while Coloured students exhibited positive insider-bias, and offers made by Whites students did not depend on the race of the partner.

The analysis however does not control for the correlates of race and in particular, for differences in income among proposers and partners, and as Burns (2006:819) acknowledges, there is a concern that what is read as differences in trusting behaviour may be differences in "other-regarding preferences such as altruism". ${ }^{3}$ Moreover, the

\footnotetext{
${ }^{3}$ The study also does not investigate how well self-reported measures of trust map onto behavioural responses.
} 
sample is restricted to a group of young adults, all with similar educational attainment, and given that age and education may be important predictors of trust, the results cannot be generalized.

An experimental research design offers many advantages over survey questions to studying the determinants of trust. It does not rely on attitudinal data (what people say they would do, which requires people to be truthful), but rather on what is observed (how people behave). It is also not subject to problems of how survey questions on trust are interpreted (Glaeser et al 2000:815). However, it is also limited, typically by the difficulties involved in identifying a sample which reflects the heterogeneity of society. Consequently, survey questions administered to a nationally representative population remain an important source of data for exploring the determinants of trust. The value of these data and the conclusions that can be drawn, of course depend on the nature and quality of the survey questions asked.

In this study, we make use of data from the first wave of the National Income Dynamic Study (NIDS) conducted in 2008. NIDS is a nationally representative household survey collecting detailed household and individual information on approximately 7,300 households and 28,000 individuals in South Africa. NIDS is the first national household survey which included questions on trust, asked of all adults (aged 15 years and older). Two questions are included:

"Imagine you lost a wallet or purse that contained R200 and it was found by someone who lives close by. Is it very likely, somewhat likely or not likely at all to be returned with the money in it?"

"Imagine you lost a wallet or purse that contained R200 and it was found by a complete stranger. Is it very likely, somewhat likely or not likely at all to be returned with the money in it?"

For each question, the respondent was given three possible (ranked) answers: very likely $=1$; somewhat likely $=2$; and not likely at all $=3$

The framing of these questions may offer a number of advantages over the standard survey trust question from the WVS and U.S. based surveys. First it allows for a ranking of expectations of trust, and does not represent trust and caution as binary alternatives. Second, it distinguishes between trust of "someone who lives close by" (neighbours) and trust of "complete strangers", providing the opportunity to investigate how expectations of trust change as the radius of trust widens. Third, rather than requiring respondents to report on trust as some general concept without a particular context, the question specifies the scope of trust, viz. the likelihood that a lost wallet will be returned.

However, a number of problems will complicate the interpretation of responses. First, the question omits information about how the wallet could be returned to its owner, because it does not specify that the wallet includes the owner's identity or address. Responses may therefore reflect expectations about both trust and the logistical likelihood of the wallet 
being returned. Second, reference to a "complete stranger" may have been designed to elicit information on generalized trust, but the same problem of interpretation which applies to "most people" would also be relevant here. Respondents may not imagine a complete stranger in abstract terms; rather, they may implicitly attach a probability weight to the identity of a stranger. In particular, given that 80 per cent of the population in South Africa is Black, respondents may visualize a complete stranger as being Black. Third, the value of the income in the wallet (R200), and therefore the associated risk, will vary greatly among respondents, and particularly along racial lines. In 2008, R200 represented about 23 per cent of average per capita monthly household income among Blacks, about 16 per cent among Coloureds, six per cent among Indians, and less than three per cent among Whites. In this case, not controlling for the socio-economic status of respondents may substantially bias race differences in trust.

In addition to questions on trust, NIDS collected a wide array of information on the socio-economic characteristics of individuals and the households in which they live. In particular, the survey is distinctive in that it asks respondents not only about the income which they received but also where respondents think they rank in the income distribution of their village or suburb. Perceptions of relative income have been shown to differ significantly from actual relative income in NIDS, with Blacks the most likely to underestimate their actual ranking in the income distribution (Posel and Casale 2011). The survey also included a set of questions about the nature of interactions among neighbours, including how common it is that neighbours help each other out and the extent to which burglary and theft are perceived as problems in the neighbourhood.

In this study, we investigate race differences in trust in South Africa, comparing reported measures of trust of individuals who live close by (neighbours) and of strangers. We are concerned particularly with how race differences in trust are affected by a range of individual, household and neighbourhood controls that typically are not included in an experimental design. A key focus is the extent to which race differences in both absolute and relative income mediate differences in the willingness to trust. In addition to objective measures of individual income and average area income, which are often tested as predictors of trust, we also consider how individuals' perceptions about their income position are related to trust.

\section{Methods and descriptive statistics}

Overall, South African adults (aged 15 years and older) report very low levels of trust. In contrast to the U.S., where approximately 40 per cent of adults report that most people can be trusted (Glaeser et al 2000, Alesina and La Ferrara 2002), only 24 per cent of South African adults expect it somewhat or very likely that a lost wallet found by someone living close by would be returned. However, trust of neighbours is also considerably higher than trust of strangers: only 12 per cent of all respondents thought there was at least some likelihood that a wallet found by a stranger would be returned. Although individuals are more willing to trust neighbours than strangers, Table 1 shows that those who trust neighbours are more likely also to trust strangers. Among 
respondents who thought it very likely that a neighbour would return a lost wallet, more than a third reported that it was very, or somewhat, likely that a stranger could be trusted. In contrast, among those who did not trust someone who lives close by, only five per cent thought it somewhat or very likely that a stranger would return a lost wallet.

Table 1. Relationship between trusting neighbours and strangers

\begin{tabular}{|c|c|c|c|c|}
\hline & \multicolumn{3}{|c|}{ Trust of strangers } & Total \\
\hline Trust of neighbours & 1 & 2 & 3 & \\
\hline 1 (not likely) & $\begin{array}{r}95.21 \\
82.24\end{array}$ & $\begin{array}{l}2.74 \\
\quad 26.22\end{array}$ & $\begin{array}{l}2.05 \\
\quad 37.29\end{array}$ & $\begin{array}{l}100 \\
75.92\end{array}$ \\
\hline 2 (somewhat likely) & $\begin{array}{r}65.36 \\
10.46\end{array}$ & $\begin{array}{r}31.43 \\
55.64\end{array}$ & $\begin{array}{ll}3.21 & \\
& 10.85\end{array}$ & $\begin{array}{l}100 \\
14.07\end{array}$ \\
\hline 3 (very likely) & $\begin{array}{r}64.03 \\
7.30\end{array}$ & $\begin{array}{r}14.39 \\
18.13\end{array}$ & $\begin{array}{r}21.58 \\
51.86\end{array}$ & $\begin{array}{l}100 \\
10.01\end{array}$ \\
\hline Total & $\begin{array}{ll}87.99 & \\
& 100\end{array}$ & $\begin{array}{ll}7.94 & \\
& 100\end{array}$ & $\begin{array}{ll}4.17 & \\
& 100\end{array}$ & $\begin{array}{l}100 \\
100\end{array}$ \\
\hline
\end{tabular}

Source: Own calculations, National Income Dynamics Study (NIDS) 2008

Lower levels of trust among South Africans may be a consequence of South Africa becoming a democracy only in recent years. The work of Ingelhart (1990) and of Muller and Seligson (1994), for example, suggests a positive correlation between trust in other people and the longevity of democratic arrangements, and democratic elections for all South Africans were first held in 1994. ${ }^{4}$ Lower levels of trust may also reflect differences in how questions on trust are framed in the surveys. In the South African survey, individuals are given a particular scope of trust, whereas the WVS question, used also in studies of trust for the U.S., does not specify what most people are to be trusted with. It seems probable that given high rates of unemployment, poverty, inequality and crime, South African adults would have particularly low expectations that a wallet containing money would be returned.

Even in the context of low trust, however, individuals are far more likely to trust their neighbours than strangers. There are a number of explanations for this finding. Neighbourhoods provide a context within which repeated social interactions can occur, thereby fostering relations of trust. Neighbourhoods in South Africa are also highly segregated, not only along socio-economic lines but also racially, and greater trust in neighbours may reflect a tendency for people to extend trust more readily to those with similar characteristics. ${ }^{5}$ A positive relationship between trust of neighbours and trust of strangers may indicate that individuals who have had positive experiences with neighbours are more willing to broaden their trust to those they do not know; it may also reflect a more general "disposition" to trust among some respondents (Wrightsman 1966).

\footnotetext{
${ }^{4}$ Endogeneity issues complicate this interpretation however, as the length of a stable democracy may itself be a function of interpersonal trust.

${ }^{5}$ Differences in the expectation that a wallet would be returned by a neighbour or a stranger may also reflect differences in the expected effort involved in returning the wallet.
} 
Table 2 describes considerable racial variation in reported levels of trust in South Africa, but particularly in trust of neighbours. In comparison to other race groups, a far larger proportion of Whites thinks it somewhat or very likely that a lost wallet found by a neighbour would be returned. However, differences in reported trust of neighbours and strangers are also most dramatic among White respondents: whereas more than 50 per cent of Whites would trust a neighbour, only approximately 13 per cent would trust a stranger to return a lost wallet. Almost equal shares of Whites and Blacks have these expectations of a stranger, and trust of a stranger remains significantly lower among Coloureds and Indians.

Table 2. Somewhat or very likely that a lost wallet would be returned by neighbours or strangers

\begin{tabular}{l|l|l}
\hline & Neighbours & Strangers \\
\hline Black & 0.237 & 0.134 \\
Coloured & $(0.004)$ & $(0.003)$ \\
& 0.139 & 0.055 \\
Indian & $(0.008)$ & $(0.005)$ \\
White & 0.217 & 0.069 \\
& $(0.028)$ & $(0.017)$ \\
\hline \hline
\end{tabular}

Source: Own calculations, National Income Dynamics Study (NIDS) 2008

Note: Standard errors are in parentheses. The sample is all adults aged 15 years and older.

An initial reading of these race differences in reported trust may suggest that in-group bias is particularly strong among Whites. Furthermore, if respondents assume that a stranger is more likely to come from the majority Black population, then Whites also display higher levels of trust than either Indians or Coloureds towards out-group members, and they almost as likely to trust "someone Black" as are Blacks themselves. However, there are many characteristics that are correlated with race and which may be expected systematically to affect reported levels of trust, thereby confounding simple comparisons.

To explore racial variation in trust further, we estimate separate ordered probit regressions for trust of neighbours $\left(\mathrm{T}^{\mathrm{n}}\right)$ and of strangers $\left(\mathrm{T}^{\mathrm{s}}\right)$, where we re-rank the dependent variables in ascending order of trust (from 1, "not likely" to 3, "very likely"):

$T_{i}^{n}=f\left(R_{i}, Y_{i} X_{i}, N_{i}\right)+\varepsilon$

$T_{i}^{s}=f\left(R_{i}, Y_{i} X_{i}, N_{i}\right)+\varepsilon$

In addition to the race of individual $\mathrm{i}\left(\mathrm{R}_{\mathrm{i}}\right)$, the regressions control for socio-economic status $\left(\mathrm{Y}_{\mathrm{i}}\right)$, as well as a range of other individual characteristics $\left(\mathrm{X}_{\mathrm{i}}\right)$, and neighbourhood characteristics $\left(\mathrm{N}_{\mathrm{i}}\right)$. 
Socio-economic status is measured both at the individual level (by the log of average per capita household income) and at the neighbourhood level (as the log of mean neighbourhood income). In addition to absolute income, we also consider two sets of measures of relative income. Actual income inequality in the neighbourhood is proxied by the Gini coefficient of per capita household income in the neighbourhood. Perceived relative income is measured through a question which asked individuals where they thought their household ranked in terms of income in their village or suburb. We include two dummy variables equal to 1 if individuals perceive their household as having income above the average income of the suburb (the richest class of households), or average income (the middle class), with below average income (the poorest class) as the omitted category.

Individual characteristics include a quadratic in age, gender, education, marital status (married, cohabiting with a partner or divorced/widowed, with never married as the omitted category), employment status, religiousness (religious activities are somewhat or very important in the individual's life), mobility (a dummy variable equal to 1 if the individual has never moved from the suburb or village) and geo-location (urban formal, urban informal, rural or tribal). We also include a variable which identifies the number of groups an individual belongs to (for example, sports groups, study groups, youth groups, sewing clubs and savings clubs), providing some measure of the individual's social capital.

In addition to measures of neighbourhood income, the estimations also control for other neighbourhood characteristics. Two dummy variables are included which capture neighbourhood socialability (respondents report that it is fairly or very common that neighbours help each other out) and neighbourhood disorder (fairly or very common that burglary and theft occur in the neighbourhood). Where information is not collected directly on neighbourhoods, for example in the case of neighbourhood income as well as racial and income heterogeneity, we use the household cluster in which the individual lives to approximate the neighbourhood. (The sample design includes 400 clusters with approximately 20 households in each cluster.) Racial heterogeneity in each household cluster (c) is measured using a standard racial fragmentation index (Alesina and $\mathrm{La}$ Ferrera 2002), as:

$1-\sum_{R} S_{R c}^{2}$

where $S_{\mathrm{Rc}}$ represents the share of race $\mathrm{R}$ in the population of the household cluster. The index, which lies from 0 to 1 , is therefore increasing in racial heterogeneity. 
Table 3. Means and standard errors of independent variables

\begin{tabular}{|c|c|c|c|c|c|}
\hline & All adults & Black & Coloured & Indian & White \\
\hline Black & $\begin{array}{l}0.782 \\
(0.004)\end{array}$ & -- & -- & -- & -- \\
\hline Coloured & $\begin{array}{l}0.142 \\
(0.003)\end{array}$ & -- & -- & -- & -- \\
\hline Indian & $\begin{array}{l}0.015 \\
(0.001)\end{array}$ & -- & -- & -- & -- \\
\hline White* & $\begin{array}{l}0.060 \\
(0.002)\end{array}$ & -- & -- & -- & -- \\
\hline Log (per capita household income) & $\begin{array}{l}6.423 \\
(0.010)\end{array}$ & $\begin{array}{l}6.194 \\
(0.010)\end{array}$ & $\begin{array}{l}6.659 \\
(0.022)\end{array}$ & $\begin{array}{l}7.604 \\
(0.074)\end{array}$ & $\begin{array}{l}8.534 \\
(0.033)\end{array}$ \\
\hline Log (average household cluster income) & $\begin{array}{l}6.760 \\
(0.007)\end{array}$ & $\begin{array}{l}6.545 \\
(0.006)\end{array}$ & $\begin{array}{l}7.064 \\
(0.013)\end{array}$ & $\begin{array}{l}7.756 \\
(0.052)\end{array}$ & $\begin{array}{l}8.568 \\
(0.022)\end{array}$ \\
\hline Gini (by household cluster) & $\begin{array}{l}0.414 \\
(0.001)\end{array}$ & $\begin{array}{l}0.421 \\
(0.001)\end{array}$ & $\begin{array}{l}0.388 \\
(0.003)\end{array}$ & $\begin{array}{l}0.386 \\
(0.005)\end{array}$ & $\begin{array}{l}0.386 \\
(0.004)\end{array}$ \\
\hline Perceived to be in richest households & $\begin{array}{l}0.086 \\
(0.002)\end{array}$ & $\begin{array}{l}0.076 \\
(0.003)\end{array}$ & $\begin{array}{l}0.088 \\
(0.007)\end{array}$ & $\begin{array}{l}0.116 \\
(0.023)\end{array}$ & $\begin{array}{l}0.204 \\
(0.014)\end{array}$ \\
\hline Perceived to be in middle households & $\begin{array}{l}0.396 \\
(0.004)\end{array}$ & $\begin{array}{l}0.354 \\
(0.005)\end{array}$ & $\begin{array}{l}0.506 \\
(0.012)\end{array}$ & $\begin{array}{l}0.668 \\
(0.033)\end{array}$ & $\begin{array}{l}0.608 \\
(0.017)\end{array}$ \\
\hline Perceived to be in poorest households* & $\begin{array}{l}0.518 \\
(0.004)\end{array}$ & $\begin{array}{l}0.570 \\
(0.005)\end{array}$ & $\begin{array}{l}0.406 \\
(0.011)\end{array}$ & $\begin{array}{l}0.216 \\
(0.029)\end{array}$ & $\begin{array}{l}0.188 \\
(0.014)\end{array}$ \\
\hline Age & $\begin{array}{l}37.546 \\
(0.154)\end{array}$ & $\begin{array}{l}36.461 \\
(0.174)\end{array}$ & $\begin{array}{l}39.231 \\
(0.384)\end{array}$ & $\begin{array}{l}39.065 \\
(1.167)\end{array}$ & $\begin{array}{l}47.250 \\
(0.610)\end{array}$ \\
\hline Female & $\begin{array}{l}0.597 \\
(0.004)\end{array}$ & $\begin{array}{l}0.598 \\
(0.005)\end{array}$ & $\begin{array}{l}0.607 \\
(0.011)\end{array}$ & $\begin{array}{l}0.593 \\
(0.035)\end{array}$ & $\begin{array}{l}0.558 \\
(0.018)\end{array}$ \\
\hline No schooling* & $\begin{array}{l}0.132 \\
(0.003)\end{array}$ & $\begin{array}{l}0.151 \\
(0.004)\end{array}$ & $\begin{array}{l}0.094 \\
(0.007)\end{array}$ & $\begin{array}{l}0.030 \\
(0.012)\end{array}$ & $\begin{array}{l}0.003 \\
(0.002)\end{array}$ \\
\hline Grade 1 to grade 7 & $\begin{array}{l}0.239 \\
(0.004)\end{array}$ & $\begin{array}{l}0.248 \\
(0.004)\end{array}$ & $\begin{array}{l}0.301 \\
(0.011)\end{array}$ & $\begin{array}{l}0.171 \\
(0.027)\end{array}$ & $\begin{array}{l}0.004 \\
(0.002)\end{array}$ \\
\hline Grade 8 to grade 11 & $\begin{array}{l}0.395 \\
(0.004)\end{array}$ & $\begin{array}{l}0.402 \\
(0.005)\end{array}$ & $\begin{array}{l}0.415 \\
(0.012)\end{array}$ & $\begin{array}{l}0.387 \\
(0.035)\end{array}$ & $\begin{array}{l}0.260 \\
(0.016)\end{array}$ \\
\hline Grade 12 (Matric) & $\begin{array}{l}0.143 \\
(0.003)\end{array}$ & $\begin{array}{l}0.132 \\
(0.003)\end{array}$ & $\begin{array}{l}0.125 \\
(0.008)\end{array}$ & $\begin{array}{l}0.221 \\
(0.029)\end{array}$ & $\begin{array}{l}0.312 \\
(0.017)\end{array}$ \\
\hline Post-matric & $\begin{array}{l}0.091 \\
(0.003)\end{array}$ & $\begin{array}{l}0.068 \\
(0.003)\end{array}$ & $\begin{array}{l}0.064 \\
(0.006)\end{array}$ & $\begin{array}{l}0.191 \\
(0.028)\end{array}$ & $\begin{array}{l}0.421 \\
(0.018)\end{array}$ \\
\hline Married & 0.286 & 0.241 & 0.358 & 0.573 & 0.622 \\
\hline
\end{tabular}


Living together

Divorced/widowed

Never married*

Employed

Religious activities important

Never moved

Urban formal*

Urban informal

Rural

Tribal

Number of groups

Neighbours help out

Crime a problem in neighbourhood

Race fragmentation index

Sample (N)

Source: Own calculations, National Income Dynamics Study (NIDS) 2008

Note: Standard errors are in parentheses. The sample is all adults aged 15 years and older. * Omitted variables in the ordered probit regressions.
(0.017)

(0.006)

0.160

(0.013)

0.175

(0.014)

0.592

(0.018)

0.885

(0.011)

0.128

(0.012)

0.894

(0.011)

0

0.102

(0.011)

0.004

(0.002)

0.385

(0.034)

0.552

(0.018)

0.291

(0.016)

0.306

(0.008) 781 
The means and standard errors of the independent variables are reported in Table 3, both for the full sample of adults as well as for the four race sub-samples. The statistics describe persistent racial differentiation in income at both the individual and the neighbourhood level, with Whites and Blacks representing the two extremes of the income hierarchy. Mirroring their actual position in the income distribution, Whites are also the most likely to perceive that they live in the richest households, while Blacks are the most likely to think that they rank among the poorest households.

Underlying these racial differences in income are large differences in educational attainment and in employment status. Whereas approximately 73 per cent of White adults had completed at least a Grade 12 (or Matric) education, this applied to a little over 40 per cent of Indian adults, and only about 20 per cent of Black and Coloured adults. In comparison to other adults, employment rates are also highest among Whites and lowest among Blacks, with only 37 per cent of Black adults in employment compared to 59 per cent of Whites.

Racial differentials in socio-economic status are evident also in residential patterns, with Whites the most likely, and Blacks the least likely, to be living in urban formal areas. The majority of Blacks are still resident in rural locations, and particularly in tribal areas, partly explaining why Blacks are also considerably more likely than other groups to live in racially homogenous neighbourhoods. Neighbourhoods in which Black adults reside are distinctive further in the extent to which neighbours are reported to help each other out, with 66 per cent of Blacks identifying this as a fairly or very common occurrence, compared to 44 per cent of Indians, 55 per cent of Whites and 58 per cent of Coloureds. In the next section, we investigate how these differences in the socio-economic characteristics of individuals and the neighbourhoods in which they live, affect race differences in reported trust.

\section{Results}

We first estimate the determinants of trust of neighbours, and then trust of strangers, but we use the same independent variables in both sets of regressions, and follow the same order of estimation. In the initial regression for trust of neighbours, shown in the first column of Table 4, only race dummy variables are included as predictors, with Whites as the omitted category. Mirroring the descriptive statistics presented in the previous section, other race groups are significantly less likely than Whites to report that they trust people who live close by.

However, once the estimation controls for differences in the absolute and relative income of individuals, and of the neighbourhoods in which they live (regression II in Table 4), race differences in trust narrow considerably. This is particularly evident in the comparison between Blacks and Whites, where the negative coefficient on the Black variable falls by almost eighty per cent. This suggests that a key explanation for the higher levels of trust of neighbours reported by White South Africans is that Whites have higher income and live in richer neighbourhoods. 
Trust of neighbours rises significantly with the individual's per capita household income. Richer people may be more trusting of neighbours if the ability to elicit trustworthy behaviour increases with income (Glaser et al 2000: 839) or if higher income acts as insurance when trusting neighbours incorrectly. The relationship between economic status and trust is further supported by our relative income measure, where individuals who perceive that they live in the richest households in their village or suburb are significantly more trusting of neighbours than those who perceive that they live in the poorest households. The absolute income of the neighbourhood (proxied by average per capita household cluster income) is also a positive and significant predictor of trust. One explanation for why trust of neighbours would rise as neighbourhood income increases is if acting in a trustworthy manner is a luxury good, which is "consumed disproportionately by people with high incomes" (Glaeser et al: 818). As average neighbourhood income rises therefore, so the likelihood of a neighbour acting in a trustworthy way may also be seen to increase. Analogously, income inequality in the area reduces reported trust, although this effect is not statistically significant.

In regression III, with the inclusion of additional controls for individual and neighbourhood characteristics, the negative coefficients on the race dummy variables fall further, and differences in reported trust of neighbours are no longer statistically significant between Whites, and Blacks or Indians. These changes partly reflect race differences in educational attainment, particularly at completed secondary and post secondary levels. Consistent with a number of studies (cf. Glaeser et al 2000, Alesina and La Ferrara 2002, Li et al 2005) more educated individuals in our sample report significantly higher levels of trust. Possible explanations for this finding are analogous to those for why income would have a positive effect on trust. Trusting behaviour and trustworthiness may both rise with education, and more educated individuals may be more likely to interact with other educated individuals (Glaeser et al 2000:818).

However, all race differences in trust of neighbours are not eliminated in the final estimation. Coloureds remain strongly and significantly less likely to trust their neighbours than any other racial group in South Africa even after controlling for income, as well as other individual and neighbourhood characteristics. Of the three racial minorities, Coloureds are the least likely ever to have moved from their district of birth, they live in more racially homogenous neighbourhoods and they have the lowest economic status. However, persistently lower levels of trust among Coloureds may indicate that there are other distinguishing characteristics for which we do not control, or control adequately in the estimations. For example, the majority of Coloureds in the Western Cape live in the Cape Flats, an area south-east of Cape Town, where crime rates are particularly high and are linked to the strong presence of gangs (Steinberg 2004). Yet, Coloured respondents in the NIDS survey are the least likely to report that theft or burglary is a problem in their neighbourhood, suggesting that the extent of criminality is not being captured in the data. Although the perceived likelihood of burglary and theft in the neighbourhood is negatively related to reported trust of neighbours, it is insignificant in the pooled regression, as well as in a separate regression for the Coloured sample (although the coefficient is more strongly negative). 
Table 4. Ordered probit regressions estimating reported trust of neighbours

\begin{tabular}{|c|c|c|c|}
\hline & I & II & III \\
\hline Black & $\begin{array}{l}-0.764 * * * \\
(0.088)\end{array}$ & $\begin{array}{l}-0.199 * * \\
(0.101)\end{array}$ & $\begin{array}{l}-0.144 \\
(0.102)\end{array}$ \\
\hline Coloured & $\begin{array}{l}-1.102 * * * \\
(0.102)\end{array}$ & $\begin{array}{c}-0.688 * * * \\
(0.108)\end{array}$ & $\begin{array}{l}-0.680 * * * \\
(0.106)\end{array}$ \\
\hline Indian & $\begin{array}{l}-0.800 * * * \\
(0.149)\end{array}$ & $\begin{array}{l}-0.575 * * * \\
(0.164)\end{array}$ & $\begin{array}{l}-0.281 \\
(0.175)\end{array}$ \\
\hline Log (per capita household income) & & $\begin{array}{l}0.056 * * * \\
(0.164)\end{array}$ & $\begin{array}{l}0.028 \\
(0.021)\end{array}$ \\
\hline Log (per capita household cluster income) & & $\begin{array}{l}0.193 * * * \\
(0.046)\end{array}$ & $\begin{array}{l}0.211 * * * \\
(0.049)\end{array}$ \\
\hline Gini (by household cluster) & & $\begin{array}{l}-0.129 \\
(0.286)\end{array}$ & $\begin{array}{l}-0.240 \\
(0.240)\end{array}$ \\
\hline Perceived to be in richest households & & $\begin{array}{l}0.407 * * * \\
(0.078)\end{array}$ & $\begin{array}{l}0.387 * * * \\
(0.078)\end{array}$ \\
\hline Perceived to be in middle households & & $\begin{array}{c}0.012 \\
(0.045)\end{array}$ & $\begin{array}{l}-0.013 \\
(0.042)\end{array}$ \\
\hline Age & & & $\begin{array}{l}-0.003 \\
(0.004)\end{array}$ \\
\hline Age $^{2}$ & & & $\begin{array}{c}0.004 \\
(0.004)\end{array}$ \\
\hline Female & & & $\begin{array}{l}-0.018 \\
(0.028)\end{array}$ \\
\hline Grade 1 to grade 7 & & & $\begin{array}{c}0.007 \\
(0.050)\end{array}$ \\
\hline Grade 8 to grade 11 & & & $\begin{array}{c}0.080 \\
(0.053)\end{array}$ \\
\hline Grade 12 (Matric) & & & $\begin{array}{l}0.148 * * \\
(0.064)\end{array}$ \\
\hline Post-matric & & & $\begin{array}{l}0.267 * * * \\
(0.067)\end{array}$ \\
\hline Married & & & $\begin{array}{l}0.094 * * \\
(0.040)\end{array}$ \\
\hline Living together & & & $\begin{array}{l}-0.067 \\
(0.059)\end{array}$ \\
\hline Divorced/widowed & & & $\begin{array}{l}0.086 * \\
(0.051)\end{array}$ \\
\hline Employed & & & $\begin{array}{c}0.054 \\
(0.038)\end{array}$ \\
\hline Religious activities important & & & $\begin{array}{c}0.019 \\
(0.054)\end{array}$ \\
\hline Never moved & & & $\begin{array}{c}0.028 \\
(0.049)\end{array}$ \\
\hline Urban informal & & & $\begin{array}{c}0.136 \\
(0.130)\end{array}$ \\
\hline Rural formal & & & $\begin{array}{c}0.196 * * \\
(0.095)\end{array}$ \\
\hline Tribal & & & $\begin{array}{c}0.061 \\
(0.087)\end{array}$ \\
\hline Number of groups & & & $\begin{array}{c}0.024 \\
(0.017)\end{array}$ \\
\hline Neighbours help out & & & $\begin{array}{c}0.198 * * * \\
(0.046)\end{array}$ \\
\hline Crime a problem in neighbourhood & & & $\begin{array}{l}-0.034 \\
(0.042)\end{array}$ \\
\hline
\end{tabular}


Race fragmentation index

Number of observations

Pseudo $\mathrm{R}^{2}$

Log-pseudolikelihood

$\mathrm{X}^{2}$

\begin{tabular}{c|c|c} 
& & -0.300 \\
12,912 & & $(0.219)$ \\
0.021 & 12,912 & 12,912 \\
-9083 & 0.041 & 0.074 \\
122.92 & -8919 & -8614 \\
\hline
\end{tabular}

Source: National Income Dynamics Study (NIDS) 2008

Note: Standard errors are in parentheses. The sample is all adults aged 15 years and older. The estimations control for the clustering of residuals across 400 household clusters. The estimations also control for the province of residence.

*** Significant at the one percent level. ** Significant at the five percent level. * Significant at the ten percent level

Of the neighbourhood controls, only average household cluster income and neighbourhood socialability are significant in the final model. Individuals who report that it is fairly or very common that neighbours help each other help report significantly higher levels of trust of neighbours, a finding that is consistent with other studies which are able to measure social interactions at a neighbourhood level (cf. Marschall and Stolle 2004). The degree of racial hetereogeneity in the neighbourhood reduces reported trust of neighbours, although in contrast to studies from U.S for example (Alesina and La Ferrara 2002), this effect is not statistically significant.

Trust of neighbours differs by location, where in comparison to individuals living in urban formal areas, those living in urban informal, tribal or rural formal areas report higher levels of trust, but the effect is statistically significant only for rural formal dwellers. ${ }^{6}$ Marital status also affects trust, with individuals who are currently or previously married significantly more likely than never married individuals to trust neighbours. ${ }^{7}$ Although the remaining controls in regression III have the expected signs, none is statistically significant. Trust of neighbours is higher among the employed, as well as among those who have never moved from their district of birth and for whom religious activities are important, and it increases in group membership. ${ }^{8}$

In Table 5, we report the results for the same three sets of regressions, where the dependent variable is now trust of strangers. As with trust of neighbours, Coloureds are significantly less likely than Whites (as well as Blacks and Indians) to trust strangers, and although the negative coefficient falls particularly with the inclusion of income controls, it remains sizeable and significant throughout. In contrast to the previous estimations, however, neither Blacks nor Indians report significantly lower levels of trust in strangers

\footnotetext{
${ }^{6}$ In an experimental survey of trust and cooperation in Russia, Gachter et al (2004) find that people from large cities are significantly less trusting compared to those from smaller cities. While not the same as looking at urban-rural location it does illustrate that further work needs to be undertaken to understand why trust differs by location.

${ }^{7}$ Ever married individuals would be more trusting of neighbours if marriage cultivates a willingness to trust or if more trusting individuals are more likely to marry.

${ }^{8}$ In contrast to other studies on the determinants of trust (Glaeser et al 2000, Alesina and La Ferrara 2002), age is not a significant predictor in our estimations. We also modelled age in terms of ten-year categories but although trust declines relative to the youngest category (younger than 25 years), none of the coefficients was significant.
} 
than Whites. Moreover, once the income variables are included in regression II, Blacks become significantly more likely than Whites to trust a stranger, and the positive coefficient increases with the inclusion of further controls in regression III. These race differences in trust of strangers are not surprising if, given that the majority of the population is Black, a stranger is assumed to be Black. Our results would then suggest that Blacks are more likely than Whites to trust someone who is Black, or that in-group trust among Blacks is stronger than out-group trust among Whites.

Like trust of neighbours, trust of strangers also increases with the respondent's income and with perceived economic status. Individuals who live in households with higher per capita income, and who perceive their income as ranking among the richest households in their village or suburb, are significantly more likely to trust a stranger to return a lost wallet. However, in contrast to the previous estimations, neighbourhood income is no longer a significant predictor of trust, perhaps because this income would not be relevant in predicting the economic status of a stranger.

Neighbourhood socialability continues to have a strong and positive effect on trust of strangers. This could indicate that positive interactions with neighbours not only increase people's trust of neighbours, but also their willingness to broaden their radius of trust to strangers. As in the previous estimations, none of the remaining neighbourhood variables is significant, and only the coefficient on the variable measuring crime in the neighbourhood changes sign, from negative when estimating trust of neighbours, to positive when estimating trust of strangers. One possible interpretation for this switch is that respondents, who perceive theft and burglary to be a problem in their neighbourhood, also view the problem as being particularly severe in their neighbourhood relative to elsewhere in the country.

Education remains a positive predictor of trust, although in comparison to trust of neighbours, the estimated coefficient is significant only for the most educated (those with post-secondary education). Two other individual characteristics change signs and gain significance when estimating trust of strangers: individuals who are employed and those who identify religious activities as important in their lives report significantly lower levels of trust of strangers. These findings would be consistent with in-group bias. Both characteristics could be seen as markers of group identity, and respondents may be more likely to assume that strangers rather than neighbours will be dissimilar. In a further regression, not reported here, we included six dummy variables for the religious affiliation of the respondent. ${ }^{9}$ In contrast to those who report no religion, all religions are associated with lower levels of trust of strangers and the coefficients are significant for all except Muslims.

\footnotetext{
${ }^{9}$ These are: Christian; Jew; Muslim; Hindu; African traditional; and other religion, with no religion as the omitted category.
} 
Table 5. Ordered probit regressions estimating reported trust of strangers

\begin{tabular}{|c|c|c|c|}
\hline & I & II & III \\
\hline Black & $\begin{array}{l}0.092 \\
(0.088)\end{array}$ & $\begin{array}{l}0.220^{*} \\
(0.128)\end{array}$ & $\begin{array}{l}0.254^{*} \\
(0.131)\end{array}$ \\
\hline Coloured & $\begin{array}{l}-0.421 * * * \\
(0.101)\end{array}$ & $\begin{array}{l}-0.323 * * * \\
(0.122)\end{array}$ & $\begin{array}{l}-0.313 * * * \\
(0.129)\end{array}$ \\
\hline Indian & $\begin{array}{l}-0.219 \\
(0.151)\end{array}$ & $\begin{array}{l}-0.166 \\
(0.136)\end{array}$ & $\begin{array}{l}0.036 \\
(0.164)\end{array}$ \\
\hline Log (per capita household income) & & $\begin{array}{l}0.042 * * \\
(0.021)\end{array}$ & $\begin{array}{l}0.029 \\
(0.022)\end{array}$ \\
\hline Log (per capita household cluster income) & & $\begin{array}{l}-0.019 \\
(0.049)\end{array}$ & $\begin{array}{l}-0.040 \\
(0.057)\end{array}$ \\
\hline Gini (by household cluster) & & $\begin{array}{l}0.029 \\
(0.268)\end{array}$ & $\begin{array}{l}-0.010 \\
(0.244)\end{array}$ \\
\hline Perceived to be in richest households & & $\begin{array}{l}0.376 * * * \\
(0.079)\end{array}$ & $\begin{array}{l}0.348 * * * \\
(0.075)\end{array}$ \\
\hline Perceived to be in middle households & & $\begin{array}{l}0.079 \\
(0.054)\end{array}$ & $\begin{array}{l}0.081 \\
(0.054)\end{array}$ \\
\hline Age & & & $\begin{array}{l}-0.001 \\
(0.005)\end{array}$ \\
\hline $\operatorname{Age}^{2}$ & & & $\begin{array}{l}0.002 \\
(0.005)\end{array}$ \\
\hline Female & & & $\begin{array}{l}-0.024 \\
(0.032)\end{array}$ \\
\hline Grade 1 to grade 7 & & & $\begin{array}{l}-0.024 \\
(0.066)\end{array}$ \\
\hline Grade 8 to grade 11 & & & $\begin{array}{l}0.038 \\
(0.075)\end{array}$ \\
\hline Grade 12 (Matric) & & & $\begin{array}{l}0.096 \\
(0.086)\end{array}$ \\
\hline Post-matric & & & $\begin{array}{l}0.227 * * \\
(0.094)\end{array}$ \\
\hline Married & & & $\begin{array}{l}0.030 \\
(0.048)\end{array}$ \\
\hline Living together & & & $\begin{array}{l}0.019 \\
(0.063)\end{array}$ \\
\hline Divorced/widowed & & & $\begin{array}{l}0.134 * * \\
(0.065)\end{array}$ \\
\hline Employed & & & $\begin{array}{l}-0.076 * \\
(0.041)\end{array}$ \\
\hline Religious activities important & & & $\begin{array}{l}-0.246 * * * \\
(0.071)\end{array}$ \\
\hline Never moved & & & $\begin{array}{l}0.046 \\
(0.049)\end{array}$ \\
\hline Urban informal & & & $\begin{array}{l}0.152 \\
(0.111)\end{array}$ \\
\hline Rural & & & $\begin{array}{l}0.126 \\
(0.108)\end{array}$ \\
\hline Tribal & & & $\begin{array}{l}0.085 \\
(0.083)\end{array}$ \\
\hline Number of groups & & & $\begin{array}{l}-0.018 \\
(0.018)\end{array}$ \\
\hline Neighbours help out & & & $\begin{array}{l}0.146 * * * \\
(0.053)\end{array}$ \\
\hline Crime a problem in neighbourhood & & & $\begin{array}{l}0.056 \\
(0.055)\end{array}$ \\
\hline
\end{tabular}




\begin{tabular}{l|l|l|l} 
Race fragmentation index & & & -0.206 \\
& & & $(0.212)$ \\
Number of observations & 12,836 & 12,836 & 12,836 \\
Pseudo R & 0.011 & 0.017 & 0.043 \\
Log-pseudolikelihood & -5652 & -5615 & -5468 \\
$\chi^{2}$ & 53.63 & 79.32 & 172.69 \\
\hline \hline
\end{tabular}

Source: National Income Dynamics Study (NIDS) 2008

Note: Standard errors are in parentheses. The sample is all adults aged 15 years and older. The estimations control for the clustering of residuals across 400 household clusters. The estimations also control for the province of residence.

*** Significant at the one percent level. ** Significant at the five percent level. * Significant at the ten percent level

\section{Conclusion}

In this study we analyse attitudinal data on trust of both neighbours and strangers collected in the 2008 National Income Dynamics Study for South Africa. We find that levels of trust in South Africa are very low, with less than a quarter of all adults reporting that they would trust their neighbours. However, as expected, South African adults are also considerably more likely to trust their neighbours than to trust strangers.

There are a number of interpretations for why self-reported trust in South Africa is so low. One possibility is that this reflects the very specific scope of trust identified in the South African survey questions, namely the likelihood that a lost wallet would be returned. Given very high poverty and unemployment rates, as well as high levels of crime, it is perhaps not surprising that a small share of South African adults would expect their wallet to be returned even if found by someone who lives close by. A lack of trust may also be a consequence of South Africa's history of racial discrimination, the only recent emergence of a democratic state, and sustained racial differences in access to resources.

Low levels of trust mask significant racial variation, with White South Africans more than twice as likely as Black South Africans, who constitute the majority population, to trust their neighbours. However, these differences in trust between Whites and Blacks narrow considerably among individuals of the same socio-economic status who live in comparably resourced neighbourhoods, and they are eliminated when the estimation controls also for a range of other individual and neighbourhood characteristics. Moreover, Blacks are not less likely than Whites to trust strangers, and rather report significantly higher levels of trust of strangers when income variables are included in the estimation. If a stranger is assumed to be Black, then our results suggest that Black South Africans are more trusting than Whites of other Blacks, a finding that would be consistent with ingroup bias.

In comparison to other races, Coloureds display the lowest trust of both neighbours and strangers, findings which remain robust in a multivariate context. Because Coloureds live in neighbourhoods with low racial fragmentation, it seems unlikely that this mistrust is 
racially motivated, and our findings may indicate rather that there are particular characteristics of Coloured communities which our estimations are not able to control for.

Trust of both neighbours and strangers increases significantly with an individual's economic status, and particularly with an individual's perceived economic status relative to that of others. The characteristics of the individual's neighbourhood also influence trusting behaviour, although neither racial fragmentation nor income inequality is a significant predictor. Rather, trust of neighbours rises significantly with neighbourhood income, and the density of positive neighbourly interactions fosters trust not only of neighbours but also of strangers.

\section{References}

Adhikari, M. (2006) "Hope, fear, shame, frustration: Continuity and change in the expression of Coloured identity in White supremacist South Africa, 1910-1994". Journal of Southern African Studies, 32(3):467-87.

Alesina, A., and La Ferrara, E. (2002) "Who trusts who?" Journal of Public Economics, 85 (2002), 207-234.

Brehm, J. and Rahn, W. (1997) "Individual level evidence for the causes and consequences of social capital". American Journal of Political Science 41: 999 - 1023.

Burns, J. (2006) "Racial stereotypes, stigma and trust in post-apartheid South Africa". Economic Modelling, 23: 805-821.

Camerer, C,. Loewenstein, G., and Prelec, D. (2005) "Neuroeconomics: How Neuroscience can inform Economics". Journal of Economic Literature, 43(1): 9-64.

Casale, D., Muller, C. and Posel, D. (2004) “Two million net new jobs': A reconsideration of the rise in employment in South Africa, 1995 - 2003". The South African Journal of Economics, 72(5): 978 - 1002.

Costa, D. L. and Kahn, M.E. (2003) "Civic engagement and community heterogeneity: An economist's perspective". Perspectives in Politics 1(1): $103-111$.

Demaris, A. and Yang, R. (1994) "Race, alienation and interpersonal mistrust". Sociological Spectrum 14(3):327-349.

Demombynes, G. and Özler, B. (2005) "Crime and local inequality in South Africa". Journal of Development Economics, 76(2): 265-292. 
Ermisch, J., Gambetta, D., Laurie, H., Siedler, T., and Noah Uhrog, S.C. (2007) "Measuring people's trust". ISER Working Paper, 2007-32.

Freitag, M. (2003) "Social capital in (dis)similar democracies: The development of generalized trust in Japan and Switzerland". Comparative Political Studies, 36: 936-966.

Gachter, S., Herrmann, B. and Thoni, C. (2004) "Trust, voluntary cooperation, and socioeconomic background: survey and experimental evidence". Journal of Economic Behaviour \& Organisation, 55:505-531.

Glaeser, E.L., Laibson, D.I., Schienkman, J.A. and Soutter, C.L. (2000) "Measuring trust". Quarterly Journal of Economics, August, pp.811-846.

Hart, A.J., Whalen, P., Shin, L., McInerney, S., Fischer, H., and Rauch, S. (2000) "Differential response in the human amygdala to racial outgroup versus ingroup face stimuli". Neuroreport, (11(11): 2351-55.

Hoogeveen, J and Özler, B. (2006) Poverty and inequality in post-apartheid South Africa: 1995-2000. Bhorat, H. and Kanbur, R. Poverty and Policy in Post-Apartheid South Africa Cape Town HSRC Press 59-94.

Ingelhart, R. (1990) Culture shift. Princeton, NJ: Princeton University Press.

Knack, S. and Keefer, P. (1996) "Does social capital have an economic payoff? A crosscountry investigation". The Quarterly Journal of Economics, 112(4): 1251.

Knack, S. and Zak, P. (2001) “Trust and growth”. Economic Journal, 111(470): 295-321.

Leibbrandt, M., Poswell, L., Naidoo, P. \& Welch, M. (2006) Measuring recent changes in South African inequality and poverty using 1996 and 2001 census data. Bhorat, $\mathrm{H}$ and Kanbur, R Poverty and Policy in Post-Apartheid South Africa Cape Town: HSRC Press 95-142.

Li, Y, Pickles, A. and Savage, M. (2005) "Social capital and social trust in Britain". European Sociological Review. 21, 109-123.

Marshall, M.J. and Stolle, D. (2004) "Race and the city: Neighbourhood context and the development of generalized trust". Political Behaviour 26(2): 125 - 153.

Miller, A.S. and Mitamura, T. (2003) “Are surveys on trust trustworthy?" Social Psychology Quarterly 66(1): 62-70.

Muller, E.N. and Seligson, M.A. (1994) "Civic culture and democracy: The question of causal relationships". American Political Science Review, 88:635-52. 
Oliver, E. J. and Mendelberg, T. (2000) "Reconsidering the environmental determinants of racial attitudes". American Journal of Political Science 44: 574-589.

Phelps, E.A., O’Connor, K.J., Cunningham, W.A., Funayama, E.S., Gatenby, J.C., Gore, J.C. and Banaji, M.R. (2000) "Performance on indirect measures of race evaluation predicts amygdala activation”. Journal of Cognitive Neuroscience, 12(5): 729-738.

Posel, D. and Casale, D. (2011) "Relative standing and subjective well-being in South Africa: The role of perceptions, expectations and income mobility". Social Indicators Research. (Electronic publication, DOI: 10.1007/s11205-010-9740-2).

Sapienza, P., Toldra, A. and Zingales, L. (2007) "Understanding trust". Unpublished manuscript.

Simpson, B., McGrimmon, T. and Irwin, K. (2007) "Are blacks really less trusting than whites? Revisiting the race and trust question". Social Forces 86(2): 525-552.

Smith, S.S. (2010) "Race and trust". Annual Review of Sociology 36: 453-475.

Tan, J. and Vogel, C. (2008) "Religion and trust: an experimental study". Journal of Economic Psychology, 29: 832-848.

Tajfel, H., Billig, M. G., Bundy, R. P. and Flament, C. (1971) "Social categorization and intergroup behaviour”. European Journal of Social Psychology, 1, 149-178.

Tschannen-Moran, M. and Hoy, W.K. (2000) "A multidisciplinary analysis of the nature, meaning and measurement of trust". Review of Educational Research 70(4):547-593.

Ulsaner, R. (2002) The moral foundations of trust. Cambridge: Cambridge University Press.

Vollan, B. (2011) "The difference between kinship and friendship: (Field-) experimental evidence on trust and punishment". The Journal of Socio-Economics, 40: 14-25.

Welch, M.R., Sikkink, D. and Loveland, M.T. (2007) "The radius of trust: Religion, social embeddedness and trust in strangers". Social Forces 86(1): 23 - 46.

Wrightsman, L.S. (1966) "Personality and attitudinal correlates of trusting and trustworthy behaviours in a two-person game". Journal of Personality and Social Psychology, 4, 328 - 332 .

Zucker, L.G. (1986) "The production of trust: Institutional sources of economic structure, 1840-1920". In: B.M. Staw and L.L. Cummings (Eds.) Research in organizational behaviour (Vol. 8), Greenwich, CT: JAI Press, pp. 55-111. 